\title{
DESORDENS PARALÓGICAS E ALÓGICAS À LUZ DA PATOLOGIA CEREBRAL
}

\author{
IsAíAs H. MeLsOHN *
}

Trataremos de sumariar as concepções de Karl Kleist sôbre as desordens do pensamento, tendo em vista que tais concepções só podem ser devidamente compreendidas à luz do conjunto da obra do grande mestre de Frankfurt.

Esboçam-se, em fins do século XIX, três correntes na investigação psiquiátrica e psicopatológica: a de Freud, a de Kraepelin e a de Wernicke. Freud visa à descrição do dinamismo psicológico e da psicogênese do indivíduo nas suas relaçōes com o grupo social, atribuindo a estas papel primordial na psicopatogenia.

Kraepelin orienta a investigaçāo segundo ideais nosológicos dos quais derivaria tôda a sua sistemática: as causas, sintomas e evolução seriam específicos para cada moléstia psiquica, de tal forma que a cada unidade nosológica corresponderia um processo patológico cerebral. Resultaram, como indubitáveis méritos do labor kraepelineano, uma descrição rica e minuciosa de quadros psicopatológicos, uma nosologia muito útil sob certos aspectos, o fecundo conceito de moléstias psiquicas endógenas. Por outro lado e limitando-lhe o alcance, logo avultaram as descriçōes clinicas de quadros mentais que não encontravam guarida nos esquemas de Kraepelin.

Wernicke procurou caracterizar as psicoses por meio da descrição de sintomas, sindromes e quadros psicopatológicos que buscava referir a mecanismos e localizações cerebrais. A literatura psiquiátrica deve a Wernicke uma fina descrição de síndromes mentais, mas, sobretudo, o primeiro grande sistema de patologia cerebral constituído pelo "Tratado das Doenças Cerebrais" publicado entre 1881 e $1883 * *$.

Discipulo de Wernicke, Kleist continua a linha de pesquisa que busca estabelecer a correlação entre a psicopatologia e a patologia cerebral. Eis porque é necessário considerar, na obra de Kleist, os estudos neurológicos

Trabalho apresentado ao Departamento de Neuro-Psiquiatria da Associaçāo Paulista de Medicina, em 5 de fevereiro de 1959.

* Psiquiatra do Hospital de Juqueri. Membro da International Psycho-Analytical Association.

** Os ulteriores sistemas de patologia cerebral seriam: a "Patologia Cerebral" de von Monakow (1897); as "Contribuições Clínicas e Anatômicas na Patologia do Cérebro" de Henschen (o volume 8", que encerra a obra, surgiu em 1924); a "Patologia Cerebral" de Kleist (1934). 
e cérebro-patológicos "pari-passu" com os estudos psiquiátricos, uma vez que êles se influenciam e se determinam reciprocamente.

Para Kleist o objetivo na pesquisa psiquiátrica é, também, a elaboração de um sistema nosológico que exprima uma unidade e correspondência entre sintomatologia clinica e processo cerebral subjacente. Esse objetivo cientifico sòmente poderia ser realizado mercê de uma integração entre investigação clínica e pesquisa anatômica e histopatológica conduzidas, uma e outra, com rigor e acuidade invulgar, a que se somaram o aprimoramento e, principalmente, a elaboração de técnicas adequadas à análise semiológica de certas funções psíquicas.

Conquanto as investigaçōes de Klejst sôbre a paţologia cerebral remontem a 1904, são os resultados hauridos dos estudos dos feridos de guerra e dos de traumatismos que formam o cerne da casuística que ilustra suas concepções sôbre a físiopatologia cerebral. Verifica-se na sua "Gehirnpathologie" (1934) como as idéias sôbre o dinamismo cerebral surgem a partir da realidade clínica e são determinadas por ela. Observa-se aí, também, que as investigações neurológicas servem de guia para as psicopatológicas. E, assim, por etapas, elabora Kleist as noções dos "sistemas cerebrais" e o papel relativo dos vários níveis e órgãos do sistema nervoso no que tange às funções neurológicas e psíquicas.

É importante analisar as noçōes dos sistemas cerebrais, na acepção de Kleist. Consideremos, para êsse fim, seus estudos sôbre os distúrbios da motilidade automática e as apraxias a que se acrescentaram os da psicomotilidade nos doentes mentais, estudos que se estenderam de 1904 a $1928^{19}$. Em 1905, em trabalho sôbre a apraxia, Kleist distingue uma forma motora (ulteriormente denominada ideocinética) e uma forma ideatória, de acôrdo, aliás, com os trabalhos de Liepmann. Em 1907, descreve uma terceira forma de apraxia a que denomina apraxia inervatória (limbocinética). Como resultados das observaçōes dos feridos de guerra, aponta uma quarta forma de apraxia, a que denomina construtiva e, por fim, descreve a apraxia da ação coordenada. Kleist estabelece a sintomatologia própria a cada uma dessas formas e a topografia das lesōes cerebrais correlatas ${ }^{8 \mathrm{n}}$.

1. Apraxia ideocinética que se manifesta sob duas formas: $a$ ) apraxia amnésica (dificuldade ou impossibilidade de executar os movimentos adequados, sendo a ação melhor realizada quando imitada); b) forma parapráxica (impossibilidade de execução dos movimentos adequados, mesmo à tentativa de imitar a ação demonstrada, havendo confusāo e ocorrêncỉa de movimentos inadequados e absurdos). Há, na apraxia ideocinética, perda dos engramas de movimentos isolados. Ela ocorre por lesōes da área 40 de Brodmann. A lesāo do hemisfério esquerdo conduz à apraxia à direita nos destros; a lesão limitada ao hemisfério esquerdo ou ao díreito não determina apraxia à esquerda nos destros, a não ser quando acompanhada de lesão calosa.

2. Apraxia inervatória (limbocinética), na qual há perda da estrutura fina dos movimentos isolados, com retardamento e falta de destreza na execucão de movimentos de partes isoladas do corpo (einzelhandlung). A lesão que determina êste 
tipo de apraxia está situada na área 6ac de Brodmann: quando das extremidades, ela resulta de lesão contralateral; a apraxia da cabeça, face e língua, nos destros, é devida à lesāo do hemisfério esquerdo.

3. Apraxia construtiva, na qual ocorrem distúrbios nos atos que conduzem à construção (shaping acts) no espaço bi ou tridimensional (construçāo com blocos, desenhos, etc.), falhando a ordenação seja por correlaçōes espaciais errôneas de partes isoladas dos objetos, seja por falha na ubicaç̃o do objeto como um todo. A fisiopatologia da apraxia construtiva consiste na perda das conexóes entre engramas óptico-espaciais e cinestésicos, funcão exercida pelo giro angular (ãrea 39 de Brodmann). Nos destros com apraxia da mão direita, encontra-se lesão à esquerda. A apraxia da māo esquerda, nos destros, implica em lesões concomitantes na regiāo posterior do corpo caloso. Existe uma agrafia construtiva (da mesma forma que uma agrafia ideocinética) por lesōes na mesma regiāo e na qual ocorrem êrros espaciais na escrita de letras isoladas ou de palavras.

4. Apraxia ideatória, cuja fisiopatologia somente póde ser elucidada após o conhecimento da forma construtiva. Ocorrem, aqui, érros espaciais e desordens na seqüência dos atos singulares no tempo; a apraxia ideatória deve ser considerada como combinação da apraxia construtiva e de alteração da faculdade de atuar em sucessão adequada. Em se tratando das mãos, a apraxia ideatória é encontrada em lesōes que incluem o gjro angular e o giro supramarginal; nāo é possivel distinguir, nas extremidades, a apraxia ideocinética da ideatória (lesōes da área indiferenciada 7 de Brodmann, do lobo parietal, em sua região superior).

5. Apraxia da ação coordenada, na qual a ação dos movimentos singulares e coordenados no tempo não se realiza, de tal modo que os atos apenas se iniciam ou são executados por forma abreviada. Trata-se de sindrome por lesão bilateral dos campos 10 de Brodmann.

Detivemo-nos na enumeração e descrição, ainda que sucinta, das apraxias, porque a análise realizada por Kleist permitiu a elucidação de problemas fundamentais da dinâmica cerebral. Verifica-se, por exemplo: 1 uma primeira oposição entre desordens apráxicas com hipocinesia (apraxia inervatória e da ação coordenada) e hipercinesias com parapraxía (apraxia ideocinética e, em parte, apraxia construtiva e ideatória); 2 - a distinção entre formas de apraxias que resultam de lesōes de regiōes posteriores do córtex cerebral (áreas 39 e 40 de Brodmann) e as que dependem de regiōes anteriores (área $6 a_{\alpha}$ e área 10), fato que sugere ser a eupraxia uma função complexa cujo pleno desempenho exige o concurso de áreas cerebrais distintas, cada uma das quais preposta a funções elementares.

Outro fato importante foi a verificação de que a apraxia com hipocinesia está ligada a lesões de centros "motores", ao passo que as hipercinesias com parapraxias são dependentes de zonas "sensoriais". Este problema, no entanto, só foi elaborado em sua forma definitiva com os estudos dos distürbios extrapiramidais e da psicomotilidade. Em trabalho realizado em 1907, Kleist analisa certos distúrbios do tono muscular e movimentos anormais de feitio atetóide, concluindo que a contração muscular prolongada corria à conta do sistema cerebelar, cuja lesāo determinaria, além disto, rigidez muscular e tremor oscilatório. Por outro lado, as lesōes dos pedúnculos cerebelares ou do núcleo denteado seriam responsáveis por movimentos de tipo corêico com hipotonia e ataxia. Tais hipóteses haveriam de sofrer modificaçōes ulteriores. Mas, por volta daquela época, serviram de base para as pesquisas dos distúrbios motores nos doentes mentais, às quais Kleist dedicou dois livros publicados em $1908^{8 a}$ e $1909^{\circ b}$. Faz, aí, fina análise semiológica, descrevendo: 
1. acinesias (dos movimentos voluntários, expressivos e acessórios) com aumento do tono;

2. hipercinesias de vários tipos: a) paracinesias semelhantes aos movimentos corêicos ou atetóides; b) estados hipercinéticos expressivos; $c$ ) hipercinesias com atos em "curto circuito"; d) agitacão motora com atos impulsivos.

Tal diferenciação semiológica foi, de resto, extremamente importante para o diagnóstico diferencial de quadros psicopatológicos cujo estudo clínico ulterior por isso se tornou possivel (caracterização das formas de catatonia e das "psicoses da motilidade" de sintomatologia diversa no que tange ao setor da psicomotilidade: aquelas do círculo esquizofrênico, de prognóstico sombrio; estas, do grupo das psicoses autóctones degenerativas, benignas, pois de cura integral, sem "defeito" psiquíco) $8 \mathrm{i}, \mathbf{3 8 e}$.

O problema que surgia era, agora, determinar a topografia dos substratos anatômicos responsáveis por tais desordens. A comparação entre os sintomas psicomotores com as alteraçōes do tono muscular e com os movimentos corêicos e atetóides sugeriu a Kleist que os distúrbios psicomotores seriam devidos a lesões do sistema frontocerebelar e dos centros subcorticais a êle relacionados. Contudo, maiores esclarecimentos dependiam do conhecimento da fisiologia dêsses centros subcorticais, o que, em parte, se tornou possível em trabalhos posteriores nos quais Kleist estuda a clínica e histopatologia dos fenômenos "amiostáticos" (coréias, atetoses, tremores, torções, miorritmias, tiques, acinesia, rigidez), demonstrando ${ }^{3 e}$, pela primeira vez, a diferença funcional entre os sistemas magno e parvocelular do estriado, bem assim que os fenômenos corêicos decorrem de lesões dos grupos microcelulares do putamen e caudado $8 \mathrm{c}$.

Na revisão sôbre a fisiologia extrapiramidal e distúrbios amiostaticos sh. Kleist chega às conclusōes seguintes: 1) os aparelhos subcorticais são relativamente independentes; 2) cada aparelho subcortical possui dois grupos celulares distintos que exercem funções específicas (a) de recepcão e coordenacão e (b) de efetuação motora; 3) cada órgão subcortical possui um arranjo celular somatotópico relativo às partes corporais isoladas; 4) há especificidade de funções de cada aparelho subcortical quando considerado como um todo, ao mesmo tempo que conexāo funcional entre todos êles:

a) o pálido é, essencialmente, um aparelho de inervação; suas funcões de coordenação sāo reduzidas, limitando-se ao tronco e aos segmentos proximais dos membros;

b) o estriado é um centro de coordenaçāo altamente diferenciado;

c) nas lesóes do núcleo rubro ocorrem vários tipos de sintomas: por alterações da função receptivo-coordenadora (partes microcelulares) surgem movimentos atetóides, mioclonias e miorritmias sobretudo nas porçōes distais dos membros; por distúrbios das funções de inervação motora (talvez núcleo magnocelular) ocorre perda dos reflexos posturais e aumento do tono extensor em consequeencia da desinibição dos centros bulbares profundos (rigidez descerebrada);

d) a substância negra desempenha papel de elevada integração no plano dos automatismos: as desordens do aparelho de coordenacăo (zona compacta?) conduzem à liberação de componentes dos automatismos (tiques e abalos clônicos unilaterais; no lado oposto, miorritmias, perda de finura de movimentos e tremores de movimentos simples e sinérgicos e, finalmente, tremores da seqüência dos movimentos 
complexos); as lesões das funçōes motoras (zona reticular) determinam perda ou diminuição de automatismos (acinesia e rigidez, especialmente das partes distais);

e) embora as funçôes da radiação subtalâmica não estejam esclarecidas, Kleist julgou que suas lesões produziriam hipercineslas do tipo de balismos.

Dessa análise resultou a possibilidade de estabelecer duas ordens de distúrbios motores subcorticais: 1. com redução de movimentos e desinibição das inervaçōes tônicas; 2. com desordens da coordenação (a) de caráter arritmico e variado ou (b) de carảter rítmico, monótono. Anàlogamente, as desordens psicomotoras nas moléstias mentais podem ser filladas a dois grupos: 1. acinesias psicomotoras com sintomas tônicos; 2. hipercinesias psicomotoras (a) sob forma de vários tipos de movimentos pseudo-espontáneos (paracinesias) ou (b) com iterações monótonas e regulares.

Estas duas formas de hipercinesias psicomotoras seriam, por assim dizer, coréia e tremor num "nivel mais alto", com fundamento anatômico especial. Assim, em casos de desordens neurológicas do tipo da coréia as lesões sāo confinadas ao putamen, ao passo que nas afecçōes psiquicas com movimentos pseudo-espontâneos (paracinesias) ou com iterações, foram encontradas lesões do caudado, exclusivamente ou associadas a lesões do putamen.

Em resumo, a motilidade automática depende de várias estruturas anatômicas nas quais distinguem-se dois grupos de centros com sentido funcional diverso: a um cabe o papel de recepção e coordenação de estímulos; ao outro, a função de efetuação. É o que sucede, também, quanto à psicomotilidade, quanto à ação voluntária, quanto à linguagem e ao pensamento abstrato.

Assim, em niveis distintos da personalidade e em niveis diversos do sistema nervoso central existe um plano geral de ordenação funcional. Tudo mostra que os "sistemas cerebrais" são conjuntos de setores anatômicos onde podem ser individualizados órgãos com funçōes particulares. Entre as moléstias nervosas e mentais, algumas há que atingem órgāos específicos de tal forma que um determinado sistema funcional é comprometido.

\section{FISIOPATOLOGIA CORTICAL}

Kleist estabeleceu as funções atinentes ao tronco cerebral e as que entendem com o manto cortical.

Ao eixo cerebral correspondem funções de cuja integração resultam o temperamento, as sensações corporais, os afetos e instintos, a motilidade automática e os impulsos, a atenção, a vigília e a consciência; no plano patológico, surgem desordens correlatas, neuro ou psicopatológicas (desordens amiostáticas, com hiper ou hipocinesia, rigidez ou hipotonia, distúrbios da psicomotilidade, euforia ou depressão, perturbaçōes da atenção, da vigília e do sono, da consciência) ${ }^{8 q, 13}$.

Ao córtex cerebral correspondem as funçōes de apreensāo e integração da experiência adquirida ao contacto com o mundo externo e, também, as que permitem a subordinação da atividade - seja em seu aspecto explìci- 
tamente motor, seja quanto ao seu conteúdo ideativo ou verbal - às solicitações do mundo subjetivo e objetivo; as desordens patológicas correspondentes constituem os vários estados demenciais, os transtornos conceituais e da palavra, do impulso (para agir, falar ou pensar), as apraxias e os diversos tipos de agnosias ${ }^{80}$.

No córtex cerebral distinguem-se esferas correspondentes aos vários órgãos dos sentidos: esferas visual (occipital), táctil (parietal), auditiva (temporal), gustativa (região subcentral e insular), labirinto-miestética ou proprioceptiva (frontal), cenestésica ou interoceptiva (região órbito-cingular) e olfativa (lobo piriforme e lobo amônico). Em cada uma dessas regióes corticais há um setor sensorial e um setor motor; ademais, aos setores sensorial e motor de cada uma das esferas sensoriais do córtex cerebral, segue-se uma zona de funções psíquicas ${ }^{8 \mathrm{~m}}$.

Para exemplificar, na regiāo occipital os campos citoarquitetônicos 17,18 e 19 de Brodmann são, respeetivamente, os que exercem funçoes sensoriais, motoras e psiquicas. Na esfera auditiva há, da mesma forma, ordenação de setores anatómicos diversos em hierarquia de funções: sensoriais (área 52 para a sensação de ruidos, área 41 para a sensação de tons, área 42 para a sensação de sons); motoras (área 21 para os movimentos de escuta, de atenção auditiva); psíquícas (área 22 para a sucessão de tons de que resulta a compreensão de melodias, sucessão de sons e conseqủente compreensão de palavras e sucessão de palavras que permite a compreensāo de frases; área 37 para a compreensão de têrmos).

Portanto, no manto cortical há um plano de organização paralelo ao do eixo cerebral: com relação a um setor sensorial qualquer, há centros de função receptivo-coordenadora de estímulos e centros de função inervatória. Além disto, e como resultado da integração de ambas as funçōes em um nivel mais alto, existem órgãos cerebrais cujas funções são — atendo-nos à terminologia de Kleist - psíquicas.

A rigor, porém, a atomização das áreas corticais em tão grande número de órgãos e funçōes elementares pouco nos revelaria dos fenômenos e faculdades psicológicas se as considerássemos segundo as descrições puramente fenomenológicas ou da psicologia clássica. A êste respeito, contudo, avulta a grande contribuição de Kleist à Psiquiatria e à Psicopatologia. A descrição de um fenômeno neurológico é relativamente fácil dado o seu caráter objetivo; o mesmo não ocorre com os fenômenos mentais, pelo menos no que tange ao seu conteúdo subjetivo. Ora, foi necessário a Kleist "compreender" e intuir os fenômenos psicopatológicos para poder penetrar-lhes a essência e o mecanismo. Em Kleist, como em qualquer outro cientista, método e construção teórica marcham juntos. A exaustiva análise, a inovação de meios adequados à exploração de funções mentais que sòmente assim se deixavam descobrir, tudo conduziu à elaboração de uma psicopatologia que surgia paralela às concepções sôbre a fisiopatologia cerebral.

Por isto, é a desorganização das funções, tal como ocorre na doença, que permite a inteligência daquelas elementares que escapam à análise quando fundidas num todo harmônico no estado de higidez. 
Quando enumeramos sintomas e funções relativas a determinadas áreas corticais, isto não significa que um processo psicológico, tal como habitualmente o concebemos, dependa daquele órgão cerebral. Quando Kleist se refere ao "pensamento ativo" como relativo ao campo 46 da regiăo frontal, não pretende que o pensamento humano resulte da dinâmica de um centro celular. Trata-se, aqui, apenas de $u m$ aspecto da funçáo intelectual, que a patologja permite seja isolado. Na realidade, porém, os processos psíquicos exigem o concurso funcional de distritos anatômicos diversos cuja identificação é, no entanto, possivel.

Vimos, ao tratar das apraxias, que elas se distinguem segundo se originem de alterações de zonas anteriores ou posteriores do manto cortical; a ação explicita deve-se, pois, às relações funcionais entre centros sensoriais ou receptivo-coordenadores (parietais) e motores (frontais). A linguagem, a seu turno, implica na integração entre funções receptivas e coordenadoras (sistema auditivo temporal) e funçōes inervatórias, motoras (áreas frontais da linguagem).

O pensamento é, também, como a linguagem e a ação, composto de produções sensoriais (receptoras e ordenadoras) e motoras, as quais organizam o pensamento em formas ou estruturas ("gestaltender") $8 \mathrm{~m}$.

Deve-se entender, desta forma, como sistema cerebral, não sòmente a unidade funcional estabelecida entre os vários órgãos e áreas cerebrais de qualquer das esferas sensoriais, mas, também, a ordenação, em um conjunto solidário, de áreas c campos neurológicos e psíquicos situados em níveis e topografia diferentes, mas subordinados a uma função complexa.

\section{DESORDENS PARALOGGICAS E ALÓGICAS}

Já vimos que, não raro, os problemas neuropatológicos conduziram Kleist à elucidação de fenômenos psicopatológicos. Assim, por exemplo, o estudo das perturbações amiostáticas permitiu a Kleist penetrar a problemática dos distúrbios da psicomotilidade e das apraxias. Da mesma forma, as pesquisas das alterações da linguagem nas moléstias cerebrais por lesões focais permitiram a compreensão das desordens da linguagem nos esquizofrênicos e estas, por sua vez, das referentes ao pensamento, naqueles mesmos doentes (desordens paralógicas e alógicas).

Efetivamente, já em 191119, Kleist estabeleceu as conexōes entre as desordens da linguagem encontradas em lesōes focais do cérebro e as dos esquizofrênicos. Verificou, além disto, que, também nos esquizofrênicos, era possivel distinguir dois tipos de alteraçōes da linguagem, segundo proviessem de áreas motoras (frontais) ou sensoriais (temporais); dependem das áreas motoras os distúrbios da formação dos sons e da ordem dos sons, a pobreza de linguagem (especialmente das palavras derivadas), ao passo que são filiáveis à zona sensorial, desordens de outro tipo (incapacidade de encontrar as palavras adequadas, parafasias e paragramatismos).

Foi justamente a análise da parafasia e do paragramatismo que permitiu a Kleist ${ }^{8 d}$ a compreensão de uma desordem característica do pensamento dos esquizofrênicos a que denominou desordem paralógica. Trata-se da impossibilidade de ocorrência de uma idéia adequada ou desejada, apesar de um acêrvo mnêmico normal. Surgem, em conseqüência, lacunas do pen- 
samento, falhas nas relações entre certas idéias, evocação de idéias errôneas ("Danebendenken": literalmente, pensar ao lado; donde, a composição com os radicais gregos "para" e "logos", do têrmo paralogia), as quais Kleist, já em 1913, considerava análogas às desordens no encontro de palavras e às parafasias, porém "em um nivel mais alto", prelinguistico. Ulteriormente, verificou que êste sintoma não é exclusivo da esquizofrenia mas ocorre nos estados crepusculares epilépticos, no sonho (fisiològicamente), em lesões focais do cérebro, na confusão sintomática, nas psicoses da motilidade, na demência senil. Em trabalho publicado em $1923^{8 \mathrm{f}}$, Kleist descreveu um caso de paralisia geral com desordens paralógicas do pensamento em que pôde ser comprovada a base anatômica dêsse sintoma e no qual foi possivel demonstrar sua independência em relação às perturbações da atenção, da incoerência, da fuga de idéias e de lacunas de conhecimento. Outros resultados ${ }^{81, n}$ confirmaram as bases "localizatórias" da paralogia.

Kleist verificou que certas lesões do campo 19 de Brodmann, não tão profundas e extensas a ponto de conduzirem à agnosia óptica, determinam perturbações da contribuição óptica à ideação, tais, que configuram a desordem paralógica: "...devemos considerar a região limítrofe do lobo occipital com a terceira circunvolução temporal como a responsável pela paralogia. O déficit das representações ópticas, insuficiente embora para levar à agnosia óptica, condiciona a diminuição geral da conceituação que se manifesta em formas de faltas, de fragmentos, de confusão ou de associação confusa de conceitos" $8 \mathrm{r}$.

Ora, o fato dêsses sintomas ocorrerem na esquizofrenia, levou Kleist à conclusão de que idênticos quadros histopatológicos poderiam ser encontrados nessa moléstia ${ }^{8 g}$, o que, ulteriormente, foi confirmado pelos trabalhos de Fünfgeld 5 .

Para melhor compreensāo do que seja a desordem paralógica torna-se necessário discutir mais a fundo algumas particularidades do processo intelectivo. A cognocibilidade dos objetos realiza-se através da percepção, isto é, através de "materiais" sensiveis; tajs operaçōes atuam sôbre "imagens" e "sinais" que são a condensação de inúmeras imagens em um conceito. O processo do pensamento consiste, em sua essência, na elaboração de conceitos ${ }^{3}$ e na reunião de conceitos em juizos. Não importa, aquí, cuidar da psicogênese do conceito, de sua formação a partir de estimulos auditivos e proprioceptivos da musculatura buco-faringo-laringea (estimulos que permitem a condensaçāo de imagens de outros setores sensoriaís e sua conexão com sons, ou seja, o estabelecimento de palavras, de têrmos, da linguagem). Importa que o conceito, uma vez surgido, resulta da fusão de imagens oriundas das diversas categorias sensoriais.

A desordem paralógica consiste em deficiente elaboração dos conceitos; tal deficiência conduz à exteriorização de processos intelectuais nos quais podem ser evidenciadas lacunas e interrelaçōes ideativas errôneas.

Citemos alguns exemplos. Devemos acentuar que em todos os casos apresentados, os demais exames a que os pacientes foram submetidos permitiram verificar que não havia, pròpriamente, desconhecimento dos conceitos relativos ao problema ou ao objeto em foco. 
1. Um doente ao qual se mostra uma tesoura, diz: " $\overline{\mathrm{E}}$ um ôvo". A interpretação da tesoura como ôvo pode ser devida á forma oval das partes com que ela é manejada.

2. Interrogado sôbre a diferença entre ave e borboleta, responde: "A ave é mais alta do que a borboleta. O símbolo é a aguia. O símbolo das borboletas noturnas é a coruja". Verifica-se, aqui, confusão entre conceitos: "mais alta" em lugar de "pertence a uma espécie mais alta"; "símbolo" em vez de "exemplo"; além disto, deslocamento e contaminaçōo de conceitos: "borboleta noturna" e "coruja" referem-se aos hábitos noturnos desta ave. Poderiamos esmiucar, ainda, outra desordem importante para a caracterização dos sintomas paralógicos, qual seja a incapacidade de definir, imprescindivel para estabelecer a diferenca proposta: a definição e comparação, necessárias para subsequiente conhecimento da diferença são substituídas pelo confronto de exemplos.

3. Um doente, interrogado sôbre a diferença entre capim e palha, responde: "o capim é planta; o cavalo vive e o gado também...". Após certa hesitação em que mostra sinais de entregar-se à reflexāo, continua: "molhado e morto" e, depois, "...morto pôsto no chāo, cama que nāo se enterra". O exame permitiu concluir que o paciente tinha plena noção de que o capim é um vegetal que serve de alimento para o gado; a palha é o capim "morto" que pode ser utilizado como leito. Mas, à tentativa de encontrar êsses vários conceltos, ocorrem deslocamentos, com associação de imagens que, pertencendo embora ao circulo ideativo do conceito procurado, são insuficientes para evocá-lo e que, ao mesmo tempo, determinam o surgimento de outros conceitos: "...morto pósto no chão, cama..." em lugar de "o capim sêco é palha que se pōe no chão e serve de cama" e "...cama que não se enterra", contaminação de palha (capim morto) com entêrro.

4. Interrogado sôbre o que seja grama, um doente esquizofrênico diz: "Grama é rama; rama é cidade aberta, nasce e cresce". Ocorrem, neste caso, desordens parafásicas, ao lado de desordens paralógicas; efetivamente, pudemos evidenciar ter havido troca entre as vogais $a$ e $o$, pois o paciente referia-se, segundo apuramos, à cidade de Roma e ao filme "Roma, cidade aberta". Desordem do tipo parafásico é, ainda, a associação, em virtude dos enlaces sonoros, entre "rama" (ramos, ramaria de árvores) e "rama" como produto da modificação parafásica de "Roma". Por outro lado, como resultado da desordem paralógica há confusão entre as imagens dependentes do conceito "grama" e as relativas a "rama" e "Roma".

5. Outro doente, instado a estabelecer a diferença entre muro e cêrca, responde: "O muro é inteiro, a cêrca é vidro", pretendendo significar que a cêrca, diversamente do que sucede com o muro, nāo oculta à visāo; como se pode inferir, o paciente é capaz de estabelecer certas caracteristicas essenciais dos dois objetos, por exemplo, a estrutura "intejra" do muro e "descontínua" da cêrca e que lhe permitem apreender o "conceito da diferença"; apesar disto, há evocação de conceitos alheios (vidro) ao processo intelectual em virtude de associaçoes de imagens e representaçoes afins ("Nebenvorstellungen": literalmente, representações próximas, afins) ${ }^{\text {sf }}$.

A desordem paralógica resulta, como vimos, de perda de cabedal óptico que é, no processo de abstração, o predominante; contudo, as vivências tácteis e cinestésicas que intervêm na conceituação podem também estar perturbadas, razão pela qual o campo 39 de Brodmann pode ser igualmente responsável por êste sintoma: "Na solução de problemas intelectuais de ordem construtiva, técnica, matemática, como, também, na execução de desenhos, pinturas e trabalhos manuais, intervêm vivencias tácteis e cinestésicas. Possuo uma coleção de trabalhos manuais de esquizofrênicos que representam verdadeiras proralogias plásticas ${ }^{8 n}$, 
Os atos absurdos dos esquizofrênicos são, da mesma forma, "a expressão de uma perturbação paralógica na superestrutura ideativa dos atos" 8 n. Tal o caso de um doente que vertia azeite fervente no ouvido a fim "de destruir os tímpanos" porque a surdez tornou Beethoven genial; bebia água porque assim o exigia a Biblia; comia migalhas de pão para expulsar do corpo o demônio". Tudo revelava que "no campo da ação explícita surgiam equívocos que correspondem às paralogias citadas" $8 \mathrm{p}$.

A elaboração dos conceitos, etapa primeira do pensamento, resulta, em suma, da dinâmica dos setores "sensoriais" do córtex cerebral, ou seja, das regiōes posteriores. A perturbação paralógica é, por isto, relativa às funçōes de elaboração em sua fase receptivo-coordenadora, ao "pensamento receptivo" (no original: "aufnehmenden Denkens") nas diferentes esferas sensoriais. A paralogia assemelha-se, neste sentido, às afasias sensoriais, às apraxias sensorias e, em nível neurológico, às ataxias (que são acompanhadas, respectivamente, de parafasias e paragramatismos, de parapraxias e de dismetrias) $)^{8 n}$.

Contudo não se esgotam com as paralogias, as desordens intrínsecas ao pensamento. Se é verdade que o homem pensa por meio de conceitos (sinais abstratos de realidades concretas e individuais), não é menos exato que êle não pensa conceitos isolados; o ato mais simples do pensar é, sempre, um julgamento, isto é, uma relação entre conceitos ${ }^{17}$. A percepção mais elementar ou a mais simples vivência são, sempre e necessàriamente, atos judicativos; a percepção de uma casa não consiste, apenas, na evocação do conceito casa, mas envolve uma relação de, pelo menos, três têrmos: isto é casa.

Nem sempre se tornam conscientes, no ato intelectivo, os vários elementos do juizo; ao perceber as várias coisas que o rodeiam, o homem não tem, constantemente, consciência de juizos e relaçōes predicativas. Apesar dísto, sua atividade está inteiramente adequada às relaçōes objetivas que existem entre as coisas que o rodeiam; ora, êste comportamento subentende o conhecimento implicito ${ }^{\circ}$ daquelas relaçôes reais, objetivas. O pensamento, quer no plano da observação concreta e abstrata, quer no da meditação, implica na elaboração de relaçōes entre conceitos, reflexo subjetivo das relaçōes objetivas. Ora, essas relaçoes sāo estabelecidas por meio de categorias gramaticais (preposiçōes, conjunçōes e verbos) cujos têrmos, isoladamente, nāo se referem a nenhum objeto real; efetivamente, os têrmos de, em, por, para, e, com, se, ou, ainda que, visto que, portanto, fazer, é, andar, comer, etc., nada significam quando nāo vinculados a representaçōes determinadas.

Esses têrmos não podem ser pensados isoladamente; as palavras aqui enumeradas, porém, adquirem um conteúdo, um sentido, quando referidas a conceitos e objetos: em (ubicação, topografia), de (pertinência), para (direção, finalidade), com, $e$ (conjunção, reunião), se (subordinaçāo, condicionalidade), visto que (dedução), ou (exclusão), fazer (algo), é (ser alguma coisa). Como vemos, êstes têrmos gramaticais servem para vincular conceitos e exprimem, unidos a êstes, relaçóes e movimentos reais do mundo objetivo. Há, por outras palavras, no ato de pensar, intelecção de movimentos e de sensações de movimentos '.

Muitos embora Kleist não tivesse analisado, por forma explícita, o julgamento sob êste aspecto lógico-semântico, chegou a idênticas conclusões quanto à intervenção da propriocepção na elaboração dos juízos. Verificou, 
além disto, que há perturbações do conteúdo do pensamento caracterizadas pela escassez de relações entre conceitos; em conseqüência, um pensamento, que normalmente deveria ser expresso por um único periodo gramatical no qual as frases se unissem por meio de verbos, conjunçōes e locuçōes, o era, ao invés, por meio de proposiçōes isoladas, não vinculadas entre si e nas quais se evidenciava a penúria dessas categorias gramaticais. Tal o caso, por exemplo, de um doente que, solicitado a construir um pensamento com as palavras "caçador, espingarda e cão", diz: "o caçador caça; a espingarda é arma; o cão morde".

Observador arguto, senhor de profundo espírito analítico e assistido por um conhecimento da problemática filosófica, Kleist investe, assim, a árdua tarefa de esclarecer a fisiopatologia do processo do pensamento. Anàlogamente ao que sucede com as apraxias e as afasias, individualizou um tipo de distúrbio do pensamento devido a alterações de zonas frontais do córtex: trata-se dos distúrbios alógicos. Diz-nos êle, à página 1013 da "Gehirnpathologie" 81 :

“Tentei compreender o problema dos distúrbios frontais do pensamento e da inteligência, através das perturbaçôes psicomotoras do impulso. Minhas investigacões em doentes mentais com carência de iniciativa resultaram no fato de que coincide, com a carência de iniciativa, uma desordem "sui generis" do pensamento e que consiste em lacunas, retardo e bloqueio dos processos intelectuais.... Todavia, além dêste aspecto formal do raciocínio, muitos dos meus doentes com carência de iniciativa manifestaram deficiências do conteúdo do pensamento... Consegui, ùltimamente, evidenclar e precisar as deficièncias temáticas do pensamento em vários doentes mentais: catatônicos, hebefrênicos, paralíticos e senis.... Em contraposição ao retardamento formal do pensamento, essas lacunas de conteúdo năo deveriam ser condicionadas, como anteriormente eu havia pensado, pelos disturbios da iniciativa, mas deveriam constituir desordem autônoma. Diferenciam-se essas desordens alógicas do pensamento das paralógicas pelo fato de não surgirem equívocos (no original, Vergreifungen) e confusões (no original, Vermegungen) nas representações e conceitos dependentes de um processo intelectual, pela ausência de omissões (no original, Nichteinfallen) amnésticas de representaçoos indispensáveis, pelo fato de não ocorrerem deficiências na evocação de conceitos, como sói ocorrer nas paraloglas dos esquizofrênicos, as quais, frequientemente, atingem o nivel da agnosia.... Trata-se, no distúrbio alógico do raciocinio, muito mais que de mera falha e fragmentacão dos pensamentos. Antes de mais nada, fracassam os doentes no problema de conjugar certos conceitos dados em correlações mais elevadas, razão pela qual torna-se perturbado o pensamento combinativo e produtivo... Assim sendo, há, provàvelmente, dois distúrbios racionais, de localização diferente: o distúrbio paralógico, oriundo da região cerebral posterior, e o alógico, dependente do cérebro frontal. Como funçāo, o pensamento constitui-se de dupla produçāo, tanto do cérebro posterior, como do cérebro frontal".

Kleist denomina as funções intelectuais do lobo frontal de "ativas"; com isto não sòmente pretende diferençá-las das funçōes receptivas atinentes ao córtex posterior, como, também, acentuar um aspecto essencial, uma nova categoria funcional: a da criação ativa (no plano da psicomotilidade, da propriocepção) de relaçōes intelectuais novas, as quais subentendem um processo subjetivo de apreensão ativamente realizada e não de mera compreensão. Estabelece uma comparação com o que sucede no plano da lin- 
guagem e do aprendizado de um idioma e mostra como a compreensão de vocábulos e de frases é uma função diversa da linguagem ativamente formulada. Além disso, diferencia os conceitos de pensamento receptivo e ativo, segundo sua acepção, da análise do pensamento realizada por outras escolas psicológicas, as quais não haviam conseguido distinguir aquelas funções primordiais do ato racional. Como afirma, às páginas 1016 e 1017 da obra citada ${ }^{81}$ :

"A psicologia, ao tratar do pensamento ativo, nāo o contrapõe a um raciocinio receptivo, mas a produçōes mnêmicas. Săo diferenciados processos psiquicos produtivos e reprodutivos.

A diferença entre raciocinlo ativo e receptivo reside na matéria em que intervêm os processos mentais produtivos e reprodutivos. No que tange ao raciocinio receptivo, esta matéria consiste na formacão de conceitos que tomam parte nas percepções e reconhecimentos, nas relaçōes, significacôes, totalidades e outros dados não conscientes. As criações novas do raciocínio ativo, assim como a atividade formal do pensamento, atuam em matéria de natureza bem diversa: em movimentos, em sensações e representações de movimentos, em vivências de vigor e esfórço, em impulsos e atos volitivos".

A regiăo cortical preposta às funçōes ativas do pensamento e de cuja alteração (lesional ou meramente dinâmica) resultam as desordens que vimos de descrever corresponde à área 46 de Brodmann ${ }^{8 j, m}$. Fácil concluir-se que a alogia corresponde, no plano do pensamento, às afasias motoras no setor da linguagem e às apraxias no que diz respeito à ação explícita; pois, tanto quanto o pensamento, a ação e a linguagem exibem a dualidade funcional de regulação sensorial e execução motora. Como vimos, à apraxia parietal (ideocinética) com suas confusões motoras e amnésias de certas formas de movimentos, contrapõe-se a apraxia frontal (inervatória), caracterizada pela execução incompleta dos atos singulares; e a ação coordenada, afim ao raciocínio, pode ser perturbada por desordem intrínseca parietal (apraxia ideatória) da qual advêm movimentos anormais por falhas na sucessão temporal ou pode resultar de lesão frontal, caso em que se configura a apraxia por lacunas de movimentos e interrupçōes em sua ordenação.

Do ponto de vista semiológico, desordem paralógica e alógica têm especial valor: em primeiro lugar, são sintomas fundamentais das moléstias esquizofrênicas 8k, m; de outro lado, assumem valor "localizatório", auxiliando, destarte, o diagnóstico topográfico de lesões corticais.

A página 1015 da Gehirnpathologie ${ }^{8}$, Kleist descreve a técnica por êle idealizada para a semiologia das desordens do pensamento. Ele elaborou quatro grupos de provas: problemas relativos a conceitos, problemas de proporçāo, relação e construçāo plástica.

1. Problemas de conceitos - a) definiçóes (o que é uma casa, um cavalo, um animal doméstico, a liberdade, a religião?); b) classificação de um objeto, subordinando-o a um conceito geral (o cachorro é um ...?); c) reuniăo de vários conceitos num único (o pombo, o gavião e a galinha são ...?; o roubo, a preguiça são ...?); d) extrair, de um conceito geral, outros particulares (citar alguns metais; dar exemplos de virtudes). 
2. Problemas de proporção - a) indicar diferenças (muro e cêrca; caixa e cêsto; rio e lago); b) indicar semelhanças ou analogias (por meio de provérbios).

3. Problemas de relações (relações significativas em virtude das circunstāncias), por meio de interpretação de ilustrações ou da crítica de frases absurdas, por exemplo.

4. Problemas de construção plástica - a) de sistematização (letras ou palavras dispostas de modo desordenado devem ser reunidas em palavras ou frases); b) de complementação de um texto em que há lacunas, analisando uma ilustração cujos elementos estão incompletos, complementando raciocínios mediante respostas a certos quesitos (o que fazer quando a casa se incendeia?; quando se perde o trem?); c) combinaçōes, construindo um pensamento com alguns conceitos (gato, pássaro e gaiola; árvore, pássaro e ninho; caçador, ave e arma).

Verifica-se que alguns dos problemas propostos podem ser solucionados por meio de processos racionais cuja conclusāo implica em poucas idéias e que pode ser expressa em poucas palavras. Outros - provérbios, de relações, de construção exigem um processo ideativo complexo, em que intervêm, em grau diverso, a ordenação, a iniciativa e espontaneidade intelectual, a vivência de finalidade. Assím, atendem alguns dos problemas à investigaçāo das paralogias, ao passo que os demais prestam-se para pôr a nu os distúrbios alógicos.

\section{COMENTARIOS}

A metodologia científica não penetrou, ainda, todos os ramos da investigação psiquiátrica, o que é de lastimar quando se assiste ao extraordinário acêrvo de fatos objetivos que a cultura psicológica conseguiu reunir. No que tange à semiologia, principalmente, ela se ressente da falta de visão sintética e doutrinária dos problemas que tem como objeto.

Algumas correntes "puramente psicológicas" afirmam, ainda hoje, a absoluta independência entre psicopatologia e patologia cerebral; em outras, multiplicam-se as concepções ou perduram as que o tempo devera ter feito desaparecer. Por exemplo, aí resta, incólume o conceito impreciso de "desagregação psíquica" que veio a se constituir no repositório de abundantes descrições de fenômenos psicopatológicos, muitos dêles obscuros e mal definidos, não atestasse êle, muita vez, a falta de captação da problemática psicológica ou, simplesmente, a ausência de elaboração científica de conceitos psicológicos. Em conseqüência da "dissecação" psicológica dos quadros mentais, da difusão e emprêgo inadequado das hipóteses psicanalíticas, da análise fenomenológica e, sobretudo, mercê da influência de correntes do pensamento psiquiátrico germânico, surgiram têrmos aos quais não está vinculado nenhum conceito fixo e definido; tais os de "autismo", "desagregação psíquica" e muitos outros. E é assim que tantos setores da investigação psiquiátrica e psicopatológica continuam aderidos a uma terminologia vasada em conceitos ultrapassados, que outro mérito não possui senão o de cercear o avanço no sentido de se estabelecer uma verdadeira ciência psicológica. Que esta crítica não seja mal interpretada. São necessárias e imprescindíveis as investigações em cada um dos terrenos, o esmiuçar fenomenológico, 
a investigação psicanalítica, a pesquisa neurofisiológica e assim por diante. Mas é bem ver-se que elas possuem apenas os elementos que devem ser integrados em uma sintese superior.

Vêm a propósito tais reflexōes quando se considera o imenso da obra de Kleist. Dela destacamos, em sucinta revisão, uns poucos aspectos gerais e analisamos, mais detidamente, um problema particular. Contudo, ela se estende e se ramifica por todos os escaninhos da Psicopatologia e da Psiquiatria.

O estabelecimento dos mapas "localizatórios" das funçōes cerebrais merece destaque especial tendo em vista sua aplicação clinica nas afecçóes cirúrgicas do encéfalo 81,20 .

As noções relativas aos sistemas cerebrais trouxeram novas luzes sôbre a nosologia psiquiátrica; debalde procurar "uma raiz única para tôdas as perturbaçōes psiquicas dos esquizofrênicos; há, no entanto, uma especial predileção dos processos mórbidos esquizofrênicos, em campos psíquicos muito diferentes, para os setores do pensamento e da linguagem" $8 \mathrm{~m}$.

As esquizofrenias são concebidas como moléstias de caráter progressivo, como heredodegenerações de sistemas cerebrais ${ }^{8} \%$. As investigações catamnésticas de Kleist, Driest ${ }^{9}$, Leonhard 10a, b, Faust, Schwab 11, 12, 16a, b e Meyer "1", na Alemanha e as de Fish ${ }^{4}$, na Inglaterra, sôbre o estado residual dos doentes esquizofrênicos, tèm ratificado tal concepçāo patogênica. Efetivamente, êsses estudos evidenciaram a permanência de grupos de sintomas específicos, fato que atesta serem as manifestações clínicas a expressão de alterações geralmente irreversiveis dos sistemas cerebrais correspondentes. Todavia, os sistemas psíquicos podem ser afetados de modo transitório, ainda que por via endógena, resultando dêste fato afecções benignas, não raro confundidas com as esquizofrenias: as psicoses autóctones degenerativas ${ }^{8 i}$. Torna-se, por tal motivo, imperioso o diagnóstico diferencial preciso daquelas moléstias ${ }^{18 e}$, sabido que um diagnóstico de moléstia esquizofrênica constitui sentença definitiva de invalidez psíquica.

No plano da análise psicológica não foram menos férteis as incursões dde Kleist. E destas, a que se adentrou na investigação sôbre o trabalho intelectual se nos afigura a mais valiosa. De fato, Kleist não se limita a conceber o pensamento como função autônoma, mas encontra uma "superestrutura ideativa dos atos" $8 n$, como, também, da linguagem; vejam-se, por exemplo, suas referências às produções artísticas dos esquizofrênicos, as quais, afirma êle, constituem verdadeiras paralogias plásticas ${ }^{8 n}$. Por outras palavras, conclui pela existência de um trabalho mental de abstração que preside e configura a ação motora, a comunicação verbal e mímica, a criação artística e científica. São deduçōes de grande alcance, totalmente alheias às das correntes psicológicas em voga, à exceção, talvez, da psicologia da forma. Kleist aproxima-se, com elas, das idéias de muitos pensadores que 
situam, na base de tôda e qualquer manifestação humana, um trabalho mental de elaboração conceitual, de simbolização, trate-se da lógica matemática, da ação, da linguagem verbal, da religião, da arte ${ }^{2,14}$.

A análise filosófica e psicológica reúne, por esta forma, lógica e mito, matemática e arte, e encontra raizes mentais comuns a manifestações que se pretendiam fôssem de setores diversos do espirito; êste fato marca uma etapa decisiva para o surgimento de uma ciência do fenômeno estético e religioso, não sòmente para a compreensão do seu conteúdo, mas, sobretudo, para o entendimento de sua "forma".

De não menor importância para a psicologia sāo as inferências que se extraem sôbre o processo perceptivo; Kleist analisa a intervenção da propriocepção em qualquer ato de percepção e de conhecimento, o que subentende a existência de sensaçōes e representaçōes de movimentos (embora não conscientes) além do material de origem exteroceptiva. Exemplifiquemos: um homem vê uma criança com a mão ferida; nesta simples percepção, êle experimenta, mentalmente, todos os atos necessários para ferir ativamente a mão da criança. Em outras palavras, no plano subjetivo, produziu-se a intelecção de todos êsses atos (e dos sentimentos por êles determinados), sem os quais não se daria o conhecimento. Ora, êstes fatos coincidem, por forma rigorosa, com a descrição da dinâmica do processo psíquico feita pela escola psicanalitica; os conceitos de "introjeção" e "projeção", de "fantasia inconsciente" referem-se ao conteúdo "representativo" inconsciente de sensações - exteroceptivas e proprioceptivas -, de atos motores e sentimentos correlatos, implícito em qualquer percepção, idéia ou ato, como bem acentua Susan Isaacs ${ }^{7}$.

A identidade de pontos de vista não se limita a essa matéria. A análise do processo de elaboraçāo dos conceitos e das desordens paralógicas levou Kleist a entrever, também, o mecanismo intelectual do processo onírico.

Analogia marcante de concepçōes é a que se pode estabelecer, ainda, entre as de Kleist e de Aníbal Silveira 18a, c, d, que aplicou, ao domínio da patologia cerebral, a teoria de Augusto Comte e de Audiffrent sôbre as funções cerebrais. O que Kleist denomina de esfera labirinto-miestética ou proprioceptiva corresponde, ao que julgamos, às funções da conação na acepção de Anibal Silveira; a proprioceptividade é, a rigor, dependente de centros infracorticais e, em primeiro lugar, do cerebelo, órgão que, por isso, rege a ação (ao mesmo tempo que integra as funções vegetativas) ${ }^{21}$; o nivel cortical dessas funçōes não pode ser tido como sensorial (ou motor) na acepção rigorosa dêste têrmo, mas trata-se, no córtex, da regência de funções em nivel "psíquico". Haja vista para o fato de que as lesões corticais não conduzem a desordens intrínsecas à sensibilidade, mas a agnosias, isto é, a transtornos no plano do reconhecimento como o próprio Kleist acentua. Ademais, Kleist supõe uma regência intelectual da ação, isto é, regência em nivel da abstração, inteiramente de acôrdo com as idéias de Aníbal Silveira $18 \mathrm{a}, \mathrm{b}$. Quanto à região posterior do manto cortical, Aníbal Silveira fala em "destrutividade" e "construtividade", significando, com êstes têrmos, que, 
se trata de funções afetivas, as quais permitem a separação, seleção e sintese de impressões provindas da interocepção e exterocepção. Trata-se, é lícito concluir, da análise e síntese de imagens por entre o caos de estímulos externos e internos, imprescindiveis para a individualização e cognocibilidade dos objetos reais, isto é, de funções prepostas à elaboração do conceito. Coincidem ambos os autores, por fim, ao atribuirem ao campo 46 de Brodmann a integração, em sua etapa final, das funçōes de abstração 18a, b.

Dificil prever o impacto da obra de Kleist sôbre as indagações da Psicologia moderna. Nela estão reunidas observações de funda importância para a sintese que se impõe das conquistas da Psicopatologia, da Psicanálise, da Neurofisiologia e da Patologia cerebral.

\section{RESUMO}

A revisão das investigações de Kleist sôbre a patologia cerebral mostram como suas idéias sôbre o dinamismo surgem a partir da realidade clinica. As investigações neurológicas servem de guia para as psicopatológicas. $\mathrm{E}$, assim, por etapas, elaborou Kleist as noções dos "sistemas cerebrais" e seu papel no que tange às funções neurológicas e psiquicas. Uma função nervosa qualquer é assegurada pelo concurso de dois setores funcionais a que correspondem substratos anatômicos próprios; ao exercício complexo das funçōes da motilidade automática, por exemplo, correspondem várias estruturas anatômicas em tôdas as quais distinguem-se dois grupos de centros com sentido funcional diverso: um, a que cabe o papel de recepção e coordenação de estímulos, outro, de efetuação. Tal dualidade de funções primordiais é a base para o desempenho de atividades neurológicas ou psiquicas, ocorrendo tanto no setor da motilidade automática, como no da psicomotilidade, no da ação explícita, no da linguagem, no do pensamento abstrato.

Foi a patologia que permitiu a Kleist a separação entre dois setores funcionais prepostos a elaboração do pensamento abstrato: aos campos 19 e 39 de Brodmann correspondem funções receptivo-coordenadoras prepostas à elaboração dos conceitos; a perturbação dessas funções conduz a uma desordem que consiste na dificuldade ou impossibilidade de elaboração dos conceitos isolados: desordem paralógica. O homem, porém, não pensa por meio de conceitos isolados; reúne-os em juizos, por meio de relações predicativas. $\overline{\mathrm{E}}$ ao córtex cerebral frontal, campo 46 , que dizem respeito tais funçōes de reunião, de efetuação do pensamento discursivo. As perturbações dessas funções, por desarranjo meramente dinâmico ou por desorganização anatômica, determinam a desordem alógica. Conquanto os dois tipos sejam encontradiços em variadas moléstias por lesão cerebral - assumindo, então, o papel de sinais focais - a desordem paralógica do pensamento, descrita muitas vêzes sob o conceito impróprio e impreciso de "desagregação mental", avulta, por sua importância e relativa pureza, nas moléstias esquizofrênicas. 


\section{SUMMARY}

Paralogical and alogical disorders on the light of Kleist's cerebral pathology

Results of Kleist's researchs on brain pathology illustrate his conceptions on brain physiopathology and are disclosed in his "Gehirnpathologie", published in 1934. Kleist's ideas on brain dynamics are determined by clinical reality; the neurological researches serve as a guide to the psychopathological ones. Thus, by stages, Kleist constructs the notions of "brain systems" and their role concerned to neurological and psychic functions. Any nervous function is secured by the concourse of two functional sectors to which correspond proper anatomical substracts. Various anatomical structures, for instance, correspond to the complex execution of automatic motility but, in all these structures, there are two groups of centers with functional significance: one for reception and coordination of stimuli and another with innervatory functions (execution). Such a duality of primordial functions is necessary to complementary action for neurological or psychic functions. This is the mechanism for automatic motility, psychomotility, explicit action, language and abstract thinking.

Pathology has allowed Kleist to distinguish two functional sectors designed for the elaboration of abstract thought, namely : the posterior cortical zone (19 and 39 Brodmann's fields) to which correspond receptive-coordinating functions, designed to the working out of concepts. The disturbance of these functions brings out a peculiar disorder, consisting in a difficulty or impossibility to elaborate isolated concepts: paralogical disorder. But man does not think isolated concepts, for these are gathered to form judgments by means of predicative relationships. Those "active" functions for gathering and affecting the discursive thought are related to the anterior brain cortex (Brodmann's field 46). A disturbance of these functions, by a mere dynamic derangement or through anatomical disorganization, brings out the alogical disorder. Although these paralogical and alogical disorders are found in many diseases due to brain lesions it is in Schizophrenia that the paralogical disorder rises in importance and relative purity. Paralogical disorders have often been described with the vague and inappropriate concept of "mental dissociation".

\section{REFERENCIAS}

1. Burloud, A. - De la Psychologie a la Philosophie. Librairie Hachette, Paris, 1950.

2. CASSIRER, E. - Language and Myth. Dover Publications Inc., Nova York, 1946.

3. FATONE, V. - Logica y Teoria del Conocimiento. Kapelusz, Buenos Aires, 1951 (pág. 26).

4. FISH, F. J. - A clinical investigation of chronic schizophrenia. J. Mental Sci., 104:34, 1958. 
5. FUNFGELD, E. - Anatomisches zur Auffassung der Schizophrenie als psychische systemerkrankung. Arch. f. Psychiat., 71:2, 1924.

6. Guillaume, P. - Introduction à la Psycholcgie. Libraírie Philosophique J. Vrin, Paris, 1946 (págs. 25-52).

7. ISAACS, S. - The nature and function of phantasy. In Melanie Klein et alt.: Development in Psycho-Analysis, vol, 43, The Hogarth Press, Londres, 1952 (págs. 67-121).

8. KLEIST, K. - a) Untersuchungen zur kenntnis der psychomotorischen Bewegungstörungen bei Geisteskranken. Klinkhardt, Leipzig, 1908; b) Weitere Untersuchungen an Geisteskranken mit psychomotorischen Störungen. Klinkhardt, Leipzig, 1909; c) Anatomische Befunde bei Huntington'scher Chorea. Z. f. Neurol., 6:423, 1913; d) Uber Bewusstseinszerfall. Z. f. Neurol., 7:552, 1913; e) Zur Auffassung der Subkortikalen Bewegungstörungen (Chorea, Athetose, Bewegungsausfall, Starre, Zittern). Arch. f. Psychiat., 59:19, 1918; $f$ ) Wesen und Lokalisation der Paralogie. Zbl. f. Neurol., 33:82, 1923; $g$ ) Die Auffassung der Schizophrenien als psychische Systemerkrankungen (Heredodegenerationen). Klin. Wschr., 2:962, 1923; $h$ ) Bericht über die extrapyramidale Bewegungsphysiologie. Düsseldorf, 1926; i) vber zykloide, paranoide und epileptoide Psychosen und über die frage der Degenerationspsychosen. Schw. Arch. f. Psychiat., $23: 3,1928$; j) Gehirnpathologische und lokalisatorische Ergebnisse: Das Stirnhirn in engeren Sinne und seine störungen. Z. f. Ges. Neurol. u. Psychiat., $131: 442,1930 ; k)$ Zur hirnpathologischen Auffassung der Schizophrenen Grundstörungen: die alogische Denkstörung. Schw. Arch. f. Psychiat., 26:99, 1930; l) Gehirnpathologie. Barth, Leipzig, 1934; $m$ ) Bericht über die Gehirnpathologie in ihrer Bedeutung für Neurologie und Psychiatrie. z. f. Neurol. u. Psychiat., 158:159 e 334, 1937; n) Störungen des Denkens und ihre hirnpathologischen Grundlagen (paralogische und alogische Denkstörung). In ROGGENBAU: Gegenwartsprobleme der psychiatrisch-neurologischen Forschung. Enke, Stuttgart, 1939; o) Progresos de la Psiquiatría. Neuropsiqulatría, 1:209, 1950; $p$ ) Esquizofrenias confusas. Folia Clínica Intern., 1, 8, 1951; q) Funciones psíquicas y tronco cerebral. Actas Luso-Esp. de Neurol. y Psiquiat., 13:85, 1954.

9. KLEIST, K. DRIEST, W. - Die Katatonie auf Grund katamnestischer Untersuchungen. Die als Katatonien verkannten Degenerationspsychosen, Psychosen der Schwachsinnigen und symptomatischen Psychosen. Zbl. f. Neurol. u. Psychiat., 89:678, 1937.

10. KLEIST, K.; LEONHARD, K.; FAUST, E. - a) Die Hebephrenien auf Grund von katamnestischen Untersuchungen. Arch. f. Psychiat. u. Z. f. Neurol., 185:77, 1950; b) Die Hebephrenien auf Grund von katamnestischen Untersuchungen. Arch. f. Psychiat. u. Z. f. Neurol., 186:1, 1951.

11. KLEIST, K.; LEONHARD, K.; SCHWAB, H. - Die Katatonie auf Grund katamnestischer Untersuchungen. Formen und Verläufe der eigentlichen Katatonie. Z. f. Neurol. u. Psychiat., 168:535, 1940.

12. KLEIST, K.; SCHWAB, H. - Die verworrenen Schizophrenien auf grund katamnestischer untersuchungen. Die denkverwirrten Schizophrenien. Arch. 1 . Psychiat. u. Z. f. Neurol., 184:28, 1950.

13. KRAPF, E. E. - La patologia cerebral segun Karl Kleist. Index de Neurol. y Psiquiat., 1:1, 1938.

14. LANGER, S. K. - Philosophy in a New Key. A Study in the Symbolism of Reason, Rite and Art. New American Library of World Literat., Nova York, 1948. 
15. MEYER, G.; LEONHARD, K.; KLEIST, K. - Die paranoiden Schizophrenien auf Grund katamnestischer Untersuchungen. Die paranoide Demenz (Progressive Auto- und Somatopsychosen). Z. f. Ges. Neurol. u. Psychiat., 177:114, 1944.

16. SCHWAB, H. - a) Die katatonie auf Grund katamnestischer Untersuchungen. Die Erblichkeit der eigentlichen Katatonie. Zeit. \&. Psychiat., 163:441, 1938; b) Die verworrenen Schizophrenien auf Grund katamnestischer Untersuchungen. Die Schizophasien. Arch. f. Psychiat. u. z. f. Neurol., 182:333, 1949.

17. SERRUS, C. - Traité de Logique. Aubier, Paris, 1945 (cap. 1, pág. 12).

18. SILVeIRA, A. - a) As funções do lobo frontal. Rev. de Neurol. e Psychiat. de São Paulo, 1:196, 1935; b) Campos arquitetônicos do lobo frontal e funções da inteligêneja. Rev. de Neurol. e Psychiat. de São Paulo, 3:1, 1937; $c$ ) Lesões casuais e lesões sistemáticas do cérebro nas doenças mentais. Arq. Assist. a Psicopatas de Sáo Paulo, 2:191, 1937; d) Pslcologia Fisiológica. In O. KLINEBERG - Psicologia Moderna, São Paulo, 1953; e) Esquizofrenias e Psicoses Degenerativas de Kleist. Patogênese e psicopatologia diferenciais. Arq. NeuroPsiquiat., 17:... (junho) 1959.

19. STRAUSS, H. - Karl Kleist, his method of resiarch and its results. J. Nerv. a. Ment. Dis., 67:1-20, 132-141 e 248-260, 1928.

20. VizzotTo, S.; PIMENTA, A. M. - La Physiopathologie du Lobe Orbitaire dans son rapport avec la Leucotomie. In Anatomo-physiologie cérébrale et Biologie (Premier Congrès Mondial de Psychiatrie), Hermann \& Cie., Paris, 1952 (pág. 148).

21. WENIGER, N. - Participaçāo do cerebelo na patogenia do cāncer. Arq. NeuroPsiquiat., 17:215 (junho) 1959.

Rua Marconi, 53, 89 andar - São Paulo, Brasil. 